1 Policlinique de médecine, Département de Médecine Communautaire,

Hôpitaux Universitaires de Genève, Geneva, Switzerland

2 Department of Social Medicine, University of Bristol, UK

${ }^{3}$ Division d'Epidémiologie Clinique, Département de Médecine Communautaire,

Hôpitaux Universitaires de Genève, Geneva, Switzerland

\title{
Use of hormone replacement therapy by menopausal women: a comparison between primary care patients and the general population
}

\author{
Submitted: 25 June 2004
}

Accepted: 3 December 2004

Published Online First: 21 July 2005

\section{Summary}

Objectives: To compare frequency and patterns of hormone replacement therapy (HRT) between primary care patients and the local community.

Methods: Comparison of data from a questionnaire survey of 107 peri- and postmenopausal patients in an academic primary care clinic during 1998 to similar data from a sample $(n=241)$ of an ongoing annual epidemiological survey representative of the general population.

Results: Mean age, menopause status, age of initiation of HRT, and prior use of contraceptive pill were similar in both groups. Current HRT use tended to be lower among patients in the clinic than in the community. HRT users in the clinic were more likely to have had a surgical menopause $(34.4 \%$ vs. $16.1 \%$, $\mathrm{p}=0.04$ ) and to have used hormones for shorter periods than in the general population. Differences remained significant after adjustment in multivariate analysis.

Conclusions: Compared to the general population, patterns of HRT use in the outpatient clinic were more restrictive than recommendations on HRT that were published at the time. This is an example of how comparison of health issues between patients in medical care and a local epidemiological survey can help to understand clinical practice.

Keywords: Hormone replacement therapy - Primary care Menopausal women - General population - Prevalence.

Hormone replacement therapy (HRT) is an important health issue for postmenopausal women. Although initially prescribed only for climacteric symptom relief, HRT rapidly became a cornerstone in the prevention and treatment of postmenopausal osteoporotic fractures (Ettinger et al. 1985). Evidence from observational studies suggested potential substantial benefit of HRT in the primary and secondary prevention of coronary heart disease (CHD) after the menopause. Before 2002, experts recommended to counsel all perimenopausal and postmenopausal women about the benefits and risks of postmenopausal hormone prophylaxis. The main potential benefits expected at the time were treatment of symptoms of menopause, reduction of osteoporotic fracture' risk and reduction of coronary heart disease. These benefits were balanced against the risks of an increase in breast cancer and thromboembolic events. The American College of Physicians added that women with a hysterectomy would be likely to benefit from therapy (American College of Physicians 1992; U.S. Preventive Services Task Force 1996). However, recent randomised controlled trials (Hulley et al. 1998; Rossouw et al. 2002) have shown that estrogen-progestin therapy increases the risks of stroke, venous thromboembolism and breast cancer after five years without preventing CHD events. A recent study showed similar findings for estrogen-alone therapy of women with hysterectomy except the increased risk of breast cancer (Women's Health Initiative Randomized Controlled Trial 2004).

Prevalence of HRT use among middle-aged women varies according to socio-economic, cultural, and medical factors (Harris et al. 1999). In the USA, use in the general population ranged between $11 \%$ and $38 \%$ with the highest prevalence among menopausal women who lived on the West Coast (Brett \& Madans 1997; Johannes et al. 1994; Harris et al. 1990; Derby et al. 1993; Cauley et al. 1990; Derby et al. 1995; Brown et al. 1999; Keating et al. 1999). Uptake was lower in Europe ranging between 2\% (Crosignani 1996; 
Moorhead et al. 1997; Oddens et al. 1994; Oddens \& Boulet 1997) and 33\% in Britain (Million Women Study Collaborators 2002) and Norway (Bakken et al. 2001). Comparisons are difficult since studies were conducted at different periods, however HRT use tended to steadily increase until 2002 (Derby et al. 1993; Johannes et al. 1994; Moorhead et al. 1997; Mueller et al. 2002). Prevalence has decreased substantially since that date (Hersh et al. 2004) following recent findings and changes in recommendations (U.S. Preventive Services Task Force 2002).

Primary care physicians are in an ideal, even if difficult, position when it comes to counselling menopausal patients on hormone replacement among other health issues (Stafford et al. 1997). In Switzerland, prescription of HRT is often considered a gynaecologist's issue and we know very little about practice in primary care. Therefore, we decided to assess HRT counselling practices among primary care trainee physicians in a University Hospital outpatient clinic. We measured the prevalence and determinants of HRT use among peri- and postmenopausal women. We compared our findings with similar data from an ongoing epidemiological survey of health indicators in the population of the area (Galobardes et al. 2003). Differences observed were likely to reflect the physicians' counselling practice in the field of HRT.

\section{Methods}

We studied HRT use in two samples of peri- and postmenopausal women aged 45-65 years who were residents in the canton of Geneva, Switzerland. In November and December 1998, all female patients aged 45-65 years who consulted at the General Internal Medicine outpatient clinic of Geneva University Hospital were asked to complete an anonymous self-administered questionnaire about reproductive history and HRT use. The clinic is an ambulatory care unit of the University Hospital which is open to all adult patients in the population. Residents have three to five years of clinical experience in internal medicine and remain one to two years. There has been a tendency to over recruit patients of a lower socio-economic status, for historical reasons.

The results were compared with data obtained in 1998 from the "Health Mobile Epidemiological Unit" (BUJ Santé) project. This is an ongoing annual community-based survey of cardio-vascular risk factors among men and women aged 35-74 resident in the canton of Geneva, which is described in detail elsewhere (Galobardes et al. 2003; Morabia et al. 1997). In brief, randomly selected residents received a mail questionnaire about health status and behaviour and were invited to bring the completed questionnaire to the "Health Mobile Unit" or to offices at Geneva University Hospital.
The self-completed questionnaire included closed questions, which were identical for both samples. Participants answered questions on reproductive history and use of oral contraception (OC) and HRT. Participants in the outpatient clinic were also asked to state the type of residence visa to identify and exclude non-residents.

Participants were defined as perimenopausal if they reported menstruation in the last 12 months but not in the last two months (adapted from Brambilla's definition (Brambilla et al. 1994)) or if they reported menstruation in the last two months and fulfilled at least one of three conditions: 1) declared to be menopausal, 2) stated having irregular periods, 3) were currently taking menopausal hormones and were 50 or younger. Women were classified as menopausal with a natural menopause if they reported at least 12 months of amenorrhea (McKinlay et al. 1992) or if they had a menstruation in the last two months but were currently taking HRT and were over 50. Participants who had had a hysterectomy before natural menopause were classified as having a surgical menopause. Women with $>12$ months of amenorrhoea after radiotherapy or chemotherapy were classified as menopausal for "other" reason, while those without an identified reason for menopause were considered as "unknown" reason for menopause.

Current HRT use was defined as ongoing HRT for a duration of at least six months. Previous OC was defined as use of the contraceptive pill in the past for at least six months.

Age, nationality, reproductive history and characteristics of HRT use were compared between both populations. We performed univariate and multivariate analyses to examine associations between HRT use and other characteristics. For univariate analyses, we compared categorical variables with $\chi^{2}$ test and continuous variables with t-test. For multivariate analyses, we used logistic regression models, adjusting for potential confounders. The odds ratios (OR) obtained in these models measured the magnitude of the association between current HRT use and several sociodemographic and clinical characteristics in the clinic sample compared to the general population. We used SAS software (SAS Institute, Cary, NC, USA) for the statistical analysis.

\section{Results}

Of the 185 patients who attended the clinic, 34 recently arrived refugees were not considered residents and were excluded. Of the 151 eligible patients, 15 women either refused to participate in the study, or could not fill in the form because of the lack of an interpreter, while another nine patients left the clinic before they could be approached. Of the 127 patients ( $84 \%$ participation rate) who 
Table 1 Description of participants in the outpatient clinic and in the general population and prevalence of HRT and OC (Geneva, Switzerland, 1998)

\begin{tabular}{|c|c|c|c|}
\hline Characteristic & $\begin{array}{l}\text { Clinic } \\
\mathrm{n}=107\end{array}$ & $\begin{array}{l}\text { General } \\
\text { Population } \\
\mathrm{n}=\mathbf{2 4 1}\end{array}$ & P-value \\
\hline Age (mean \pm SD) & $55.5( \pm 5.8)$ & $55.3( \pm 5.3)$ & 0.8 \\
\hline \multicolumn{4}{|l|}{ Age distribution (\%) } \\
\hline $45-49$ & 23.4 & 14.1 & 0.06 \\
\hline $50-54$ & 18.7 & 30.3 & \\
\hline $55-59$ & 32.7 & 30.3 & \\
\hline $60-65$ & 25.2 & 25.3 & \\
\hline \multicolumn{4}{|l|}{ Swiss Nationality (\%) } \\
\hline yes & 57.0 & 76.4 & 0.001 \\
\hline no & 43.0 & 23.6 & \\
\hline \multicolumn{4}{|l|}{ Menopause status (\%) } \\
\hline perimenopausal & 29.0 & 22.8 & 0.2 \\
\hline postmenopausal & 71.0 & 77.2 & \\
\hline \multicolumn{4}{|l|}{ Type of menopause (\%) } \\
\hline natural menopause & 70.7 & 75.2 & 0.4 \\
\hline surgical menopause & 25.3 & 22.0 & \\
\hline other & 2.7 & 2.8 & \\
\hline unknown & 1.3 & 0.0 & \\
\hline \multicolumn{4}{|l|}{$\begin{array}{l}\text { Age by menopause } \\
\text { status (mean yrs } \pm S D \text { ) }\end{array}$} \\
\hline perimenopause & $49.4( \pm 3.4)$ & $50.5( \pm 4.1)$ & 0.2 \\
\hline postmenopause & $58.0( \pm 4.5)$ & $56.8(+4.7)$ & 0.05 \\
\hline \multicolumn{4}{|l|}{ Contraceptive pill (\%) } \\
\hline ever use & 56.1 & 58.5 & 0.7 \\
\hline \multicolumn{4}{|l|}{$\begin{array}{l}\text { Hormone replacement } \\
\text { therapy (\%) }\end{array}$} \\
\hline current use & 38.3 & 47.7 & 0.1 \\
\hline past use & 10.3 & 5.8 & \\
\hline never use & 51.4 & 46.5 & \\
\hline
\end{tabular}

a $\mathrm{n}=75$ in the clinic and $\mathrm{n}=182$ in the population survey (postmenopausal women only)

completed the questionnaire, 20 were excluded because they were premenopausal.

In the 1998 Bus Santé project, 337 women aged 45-65 years $(56 \%)$ responded to the postal survey, of which 96 premenopausal women were excluded. We analysed the data on the reproductive history and HRT use provided by the final sample of 241 perimenopausal and postmenopausal women. General characteristics of the participants in both populations are described in Table 1 . The mean age (55 years), use of OC, menopause status, type of menopause and age by menopause status were similar in both samples. The higher proportion of foreigners in the clinic was the only significant difference observed but prevalence of current HRT use tended to be lower among women of the outpatient clinic than in the general population ( $38.3 \%$ vs. $47.7 \%$ ).

On average, women started to take HRT at the age of 50, which is close to the median age of natural menopause (Tab. 2). When analysed by age group, current HRT use was definitely not restricted to the perimenopausal period, but
Table 2 Characteristics of current HRT users in the clinic and in the general population (Geneva, Switzerland, 1998)

\begin{tabular}{|c|c|c|c|}
\hline Characteristic & $\begin{array}{l}\text { Clinic } \\
\mathrm{n}=41\end{array}$ & $\begin{array}{l}\text { General } \\
\text { Population } \\
\mathrm{n}=115\end{array}$ & P-value \\
\hline Mean age $(+S D)$ & $56.4( \pm 5.3)$ & $56.4( \pm 4.8)$ & 0.9 \\
\hline $\begin{array}{l}\text { Age of HRT initiation } \\
(\text { mean } \pm \text { SD) }\end{array}$ & $50.5( \pm 5.6)$ & $50.2( \pm 4.2)$ & 0.8 \\
\hline \multicolumn{4}{|l|}{ Swiss nationality (\%) } \\
\hline yes & 46.3 & 73.9 & 0.0013 \\
\hline no & 53.7 & 26.1 & \\
\hline HRT duration & $5.5( \pm 5.4)$ & $6.2( \pm 3.8)$ & 0.5 \\
\hline \multicolumn{4}{|l|}{$\begin{array}{l}\text { HRT duration by age } \\
\text { group (mean } \pm S D)\end{array}$} \\
\hline $45-49$ years & $1.0( \pm 0.6)$ & $2.4( \pm 1.4)$ & 0.04 \\
\hline $50-54$ years & $4.2( \pm 3.9)$ & $4.5( \pm 3.0)$ & 0.8 \\
\hline $55-59$ years & $6.4( \pm 4.9)$ & $6.0( \pm 3.3)$ & 0.8 \\
\hline $60-65$ years & $8.0( \pm 7.0)$ & $8.9( \pm 3.6)$ & 0.7 \\
\hline \multicolumn{4}{|l|}{ HRT duration (\%) } \\
\hline 1-2 years & 41.5 & 18.3 & 0.01 \\
\hline $3-4$ years & 19.5 & 25.2 & \\
\hline$\geq 5$ years & 39.0 & 56.5 & \\
\hline \multicolumn{4}{|l|}{ Menopause status (\%) } \\
\hline perimenopause & 19.5 & 17.4 & 0.8 \\
\hline postmenopause & 80.5 & 82.6 & \\
\hline \multicolumn{4}{|l|}{$\begin{array}{l}\text { Type of postmeno- } \\
\text { pause (\%) }\end{array}$} \\
\hline natural menopause & 59.4 & 81.7 & 0.04 \\
\hline surgical menopause & 34.4 & 16.1 & \\
\hline other & 6.3 & 2.2 & \\
\hline \multicolumn{4}{|l|}{$\begin{array}{l}\text { Prior use of oral } \\
\text { contraception (\%) }\end{array}$} \\
\hline yes & 61.0 & 62.6 & 0.9 \\
\hline
\end{tabular}

was distributed relatively harmoniously over the 15 years following menopause. Similar proportions of women had previously taken OC. We observed two significant differences in HRT use between primary care patients and the general population. First, a higher proportion of short-term current HRT users (one to two years) in the clinical sample which contrasts with longer use in the community $(41.5 \%$ vs. $18.3 \%$ ). Second, a higher rate of surgical menopause among clinic patients than in the general population (34.4\% vs. 16.1).

Table 3 shows results of a logistic regression expressed as the ratio of the odds of being a current HRT user in the clinic (versus a never user) to the odds of being a current HRT user in the general population according to known determinants of HRT use. Multivariate analysis shows that, compared to the general population, women attending the primary care clinic are approximately twice less likely to be current HRT users if they had a natural menopause or were Swiss citizens. 
Table 3 Prevalence and Odds Ratio of current HRT use (versus never use) in the clinic and in the general population by different characteristics (Geneva, Switzerland, 1998)

\begin{tabular}{|c|c|c|c|c|c|c|}
\hline \multirow[t]{3}{*}{ Characteristic } & \multicolumn{4}{|c|}{ Current HRT use } & \multirow[t]{3}{*}{$\mathrm{OR}^{\mathrm{a}}$} & \multirow[t]{3}{*}{$\mathrm{Cl} 95 \%$} \\
\hline & \multicolumn{2}{|c|}{ Clinic } & \multicolumn{2}{|c|}{ General population } & & \\
\hline & $\mathbf{N}$ & $\%$ & $\mathbf{N}$ & $\%$ & & \\
\hline \multicolumn{7}{|l|}{ Age groups } \\
\hline $45-49$ & 23 & 26.1 & 32 & 28.1 & 0.7 & $(0.2-2.5)$ \\
\hline $50-54$ & 19 & 42.1 & 70 & 47.1 & 0.8 & $(0.3-2.2)$ \\
\hline $55-59$ & 30 & 56.7 & 69 & 56.5 & 1.0 & $(0.4-2.4)$ \\
\hline $60-65$ & 24 & 41.7 & 56 & 60.7 & 0.4 & $(0.2-1.2)$ \\
\hline \multicolumn{7}{|l|}{ Nationality } \\
\hline Swiss & 55 & 34.6 & 172 & 49.4 & 0.5 & $(0.2-0.9)$ \\
\hline foreign & 41 & 53.7 & 55 & 54.6 & 1.0 & $(0.5-2.4)$ \\
\hline \multicolumn{7}{|l|}{ Menopausal status } \\
\hline postmenopausal & 29 & 27.6 & 52 & 38.5 & 0.8 & $(0.4-1.4)$ \\
\hline perimenopausal & 67 & 49.3 & 175 & 54.3 & 0.8 & $(0.3-2.1)$ \\
\hline \multicolumn{7}{|l|}{ Type of menopause } \\
\hline natural menopause & 47 & 40.4 & 126 & 60.3 & 0.4 & $(0.2-0.9)$ \\
\hline surgical menopause & 16 & 68.8 & 40 & 37.5 & 3.7 & $(1.0-12.9)$ \\
\hline \multicolumn{7}{|l|}{ Prior oral contraception } \\
\hline yes & 54 & 46.3 & 131 & 55.0 & 0.7 & $(0.4-1.4)$ \\
\hline no & 42 & 38.1 & 96 & 44.8 & 0.7 & $(0.3-1.5)$ \\
\hline
\end{tabular}

$\mathrm{OR}=$ odds ratio; $\mathrm{Cl}=$ confidence interval.

${ }^{a}$ simultaneously adjusted for all other variables in the table.

\section{Discussion}

This comparative study between clinical and epidemiological data is an innovative approach to assessing differences in medical practice in the hospital versus the community. Differences observed in health behaviour between women in clinical practice and in the community can be considered an indirect indicator of the residents' approach to HRT counselling.

Prevalence of current HRT use in the outpatient clinic was $38.3 \%$, which was lower, although not significantly so, than in the general population. Clinic women with a surgical menopause used HRT significantly more often than women in the general population with the same characteristics. Also, current users in clinical practice used HRT for a shorter period (one to two years) than in the community and were less likely to be Swiss.

To our knowledge, this is the first report that directly compares the prevalence and the application of a clinical preventive guideline in a clinical context with HRT use in the general population. This is possible because of the identical methodology applied in both surveys. Characteristics of HRT use among women in medical care can therefore be directly compared with those of women living in the community, instead of solely being compared with unrelated clinical and epidemiological data.
It is important to remember that this study was conducted in the pre-WHI (Women's Health Initiative) era when longterm HRT use was recommended for the prevention of chronic disease. Since then evidence has shown that HRT carries more risks than benefits and the U.S. Preventive Services Task Force (2002) now recommends against HRT use for the prevention of chronic conditions.

In 1998, the prevalence of HRT in the clinical sample $(38.3 \%)$ could be considered high when compared to most recent studies which showed that in clinical practice uptake was rarely higher than $30 \%$ with the exception of one study which showed a prevalence of $60 \%$ (Stafford et al. 1997; Ghali et al. 1997; Wise et al. 1999; Levy et al. 2003). However, when compared to the prevalence in the population sample (47.7\%), current HRT use in the clinic appeared to be rather low. The fact that prevalence in the clinical sample was not superior to prevalence in the population is interesting since results from previous reports suggested that women in a medical setting used more hormones than the general population (Johannes et al. 1994; MacLennan et al. 1993; Ringa \& Jaussent, 1999; Zhang et al. 1999).

There may be several reasons for the tendency to low HRT use in our clinical sample. An important contributing factor to lower HRT uptake in the clinic compared to the community was probably the difference in socio-economic 
status and cultural background between the two samples. Even though migrant patients were excluded from the clinic sample, patients in the clinic had a lower socio-economic status which had consistently been associated with lower HRT use (Finley et al. 2001; Brett \& Madans, 1997; Johannes et al. 1994; Derby et al. 1993).

Medical speciality played an important part in doctors' counselling and prescribing practices regarding HRT. In Switzerland, gynaecologists work as primary care providers for women's health. This explains why all participants who took HRT in the outpatient clinic stated that the treatment was prescribed by their gynaecologist (results not shown). Gynaecologists were generally more favourable to HRT as a treatment for menopausal symptoms and for disease prevention than primary care physicians (Hemminki et al. 1993; Jolleys \& Olesen 1996; Levy et al. 2003). Thus, the level of HRT use in the population survey could very well have reflected the high level of HRT prescribing among Swiss gynaecologists. This implies that clinic patients visited less often a gynaecologist. Also, residents in the clinic could have been influenced by European authors who favoured HRT less strongly than their American counterparts (Posthuma et al. 1994; Khaw 1998). Furthermore, residents may have been more cautious in recommending long-term HRT use as they were exposed to a critical and evidence-based approach to preventive interventions during their residency training. Practising physicians in the community may have been more influenced by pro-HRT Swiss gynaecological opinion leaders.

In our study, current HRT users in medical care were more likely to have a surgical menopause than current users in the general population. This result shows that counselling by residents in the outpatient clinic focused on women with a hysterectomy, which followed the American College of Physicians' recommendations of the time (American College of Physicians 1992; U.S. Preventive Services Task Force 1996). Surgical menopause had been universally associated with HRT use (Johannes et al. 1994; Keating et al. 1999; Moorhead et al. 1997; MacLennan et al. 1993; Taffe et al. 1997; Harris et al. 1999).

The study also shows that a higher proportion of current users in the clinic took HRT for short periods than in the general population.

Current HRT users were less likely to be Swiss in the clinical sample than in the general population. It is likely that Swiss patients in the clinic came from a lower socio-economic background and therefore presented a lower uptake than Swiss women from the general population.
In general, apart from a significantly lower proportion of Swiss patients in the clinic, the two study groups are similar in relation to age and menopause characteristics. When patterns of HRT use are compared between the two populations, patients in the clinic are taking HRT differently. They tend to use less HRT, for shorter periods and preferably when they have a surgical menopause. The different pattern of HRT use emphasized by this comparative study is an indicator of the residents' clinical practice.

Our study is limited by the smaller sample in the outpatient clinic and the relatively low participation rate $(56 \%)$ of women aged $45-65$ years in the community sample. Since $29.3 \%$ of non-responders to the epidemiological survey were smokers versus $18.3 \%$ of participants (data not shown), the prevalence of HRT in the community sample could have been overestimated due to a selection bias towards a healthier lifestyle (Hemminki et al. 1993). However, smoking was not associated with current HRT use in the general population (results not shown).

The epidemiological survey provided data on average or "typical" behaviour in relation to HRT use in the community. We used this information to critically assess clinical practice in the same geographical area. We think that similar comparisons would be useful in other fields of medicine such as diabetes care or control of coronary heart disease risk factors.

In conclusion, our report shows that prevalence of HRT use in a Swiss academic general internal medicine outpatient clinic was relatively low compared to use in the community. This can be explained by socio-economic and medical factors. Compared to patterns of use in the community, HRT use in the clinic didn't fully comply with prevailing recommendations on the prevention of chronic disease. Our study proposes an innovative approach to analysing clinical practice by providing a "population perspective" which gives clinicians the opportunity to critically assess their own practice. This method could be applied to other fields of prevention.

\section{Conflicts of interest}

None

Acknowledgment

We thank Prof A. Morabia for providing the data of the Bus Santé Project and for his contribution towards designing the study, supervising the analysis and drafting the manuscript. 
Zusammenfassung

Gebrauch der Hormonsubstitutionstherapie in der Menopause: Vergleich zwischen Hausarzt-Patientinnen und der Allgemeinbevölkerung

Fragestellung: Ziel der Studie ist der Vergleich zwischen der Häufigkeit und Verschreibungsmuster für Hormonsubstitutionstherapie (HRT) zwischen Hausarzt-Patientinnen and der lokalen Allgemeinbevölkerung.

Methoden: Vergleich zwischen Daten einer 1998 durchgeführten Fragebogen-Umfrage mit 107 peri- und postmenopausalen Patientinnen einer universitären Poliklinik mit ähnlichen Daten einer Stichprobe ( $n=240$ ) einer fortlaufenden jährlichen epidemiologischen Bevölkerungsumfrage.

Ergebnisse: Mittleres Alter, Menopausestatus, Alter bei Beginn der HRT sowie früherer Gebrauch der Kontrazeptionspille waren in beiden Gruppen ähnlich. Gegenwärtiger Gebrauch von HRT war niedriger bei Patientinnen der Poliklinik. HRT-Benutzerinnen der Poliklinik hatten häufiger eine chirurgische Menopause $(34,4 \%$ vs. $16,1 \% ; p=0,04)$ und eine geringere Dauer der HRT als die lokale Allgemeinbevölkerung. Die Unterschiede blieben auch nach multivariaten Analysen signifikant.

Schlussfolgerung: Im Vergleich zur Allgemeinbevölkerung wurde die HRT in der Poliklinik weniger eingesetzt als dies die damals gültigen Empfehlungen vorsahen. Diese Studie ist ein Beispiel dafür, wie der Vergleich zwischen Patientinnen einer Poliklinik und einer lokalen epidemiologischen Studie mithelfen kann, Versorgungsaspekte in Public Health besser zu verstehen.
Résumé

Utilisation de I'hormonothérapie de substitution à la ménopause: une comparaison entre des patientes en médecine de premier recours et la population générale

Objectifs: Comparer la fréquence et l'utilisation du traitement hormonal de substitution (THS) en médecine de premier recours et dans la population générale.

Méthodes: Etude transversale par questionnaire de 107 patientes péri- et post ménopausées dans un centre universitaire de premiers recours en novembre et décembre 1998. Comparaison avec des données similaires d'un échantillon $(n=241)$ d'une étude épidémiologique annuelle représentative de la population générale.

Résultats: La fréquence d'utilisation antérieure d'une contraception orale était semblable dans les deux groupes. L'utilisation actuelle du THS avait tendance à être moins importante chez des femmes du centre universitaire que dans la population générale. Les utilisatrices du THS dans le centre avaient plus souvent une ménopause chirurgicale $(34,4 \%$ contre $16,1 \%$, $p=0,04$ ) et utilisaient les hormones pendant une durée plus courte que dans la population. Ces différences restaient significatives après analyse multivariée.

Conclusions: L'utilisation de THS dans le centre universitaire de médecine de premier recours était plus restrictive que dans la population générale par rapport aux recommandations scientifiques de l'époque sur la prescription de THS. Cette comparaison directe entre des patients suivis par des médecins et la population générale est utile pour analyser la pratique médicale.

\begin{abstract}
References
American College of Physicians (1992). Guidelines for counseling postmenopausal women about preventive hormone therapy. American College of Physicians. Ann Intern Med 117: 1038-41.
\end{abstract}

Bakken K, Eggen AE, Lund E (2001). Hormone replacement therapy in Norwegian women, 1996-1997. Maturitas 40: 131-41.

Brambilla DJ, McKinlay SM, Johannes CB (1994). Defining the perimenopause for application in epidemiologic investigations. Am J Epidemiol 140: 1091-5.

Brett KM, Madans JH (1997). Use of postmenopausal hormone replacement therapy: estimates from a nationally representative cohort study. Am J Epidemiol 145: 536-45.
Brown AF, Perez-Stable EJ, Whitaker EE, et al. (1999). Ethnic differences in hormone replacement prescribing patterns. J Gen Intern Med 14: 663-9.

Cauley JA, Cummings SR, Black DM, Mascioli $S R$, Seeley $D G(1990)$. Prevalence and determinants of estrogen replacement therapy in elderly women. Am J Obstet Gynecol 163: 1438-44.

Crosignani PG (1996). Management of hormone replacement therapy: the Italian experience. Eur J Obstet Gynecol Reprod Biol 64 Suppl: S13-S15.

Derby CA, Hume AL, Barbour MM, McPhillips $J B$, Lasater TM, Carleton RA (1993). Correlates of postmenopausal estrogen use and trends through the 1980s in two southeastern New England communities. Am J Epidemiol 137: 1125-35.
Derby CA, Hume AL, McPhillips JB, Barbour $M M$, Carleton RA (1995). Prior and current health characteristics of postmenopausal estrogen replacement therapy users compared with nonusers. Am J Obstet Gynecol 173: 544-50.

Ettinger B, Genant HK, Cann CE (1985). Longterm estrogen replacement therapy prevents bone loss and fractures. Ann Intern Med 102: 319-24.

Finley C, Gregg EW, Solomon LJ, Gay E (2001). Disparities in hormone replacement therapy use by socioeconomic status in a primary care population. J Community Health 26: 39-50.

Galobardes B, Costanza MC,Bernstein MS, et al. (2003). Trends in risk factors for lifestyle-related diseases by socio-economic position in Geneva, Switzerland, 1993-2000: health inequalities persist. Am J Public Health 93: 1302-9. 
Ghali WA, Freund KM, Boss RD, Ryan CA, Moskowitz MA (1997). Menopausal hormone therapy: physician awareness of patient attitudes. Am J Med 103: 3-10.

Harris RB, Laws A, Reddy VM, King A, Haskell $W L$ (1990). Are women using postmenopausal estrogens? A community survey. Am J Public Health $80: 1266-8$.

Harris TJ, Cook DG, Wicks PD, Cappuccio FP (1999). Ethnic differences in use of hormone replacement therapy: community based survey. BMJ 319: 610-1.

Hemminki E, Malin M, Topo P (1993). Selection to postmenopausal therapy by women's characteristics. J Clin Epidemiol 46: 211-9.

Hersh A, Stefanick M, Stafford R (2004). National use of postmenopausal hormone therapy. Annual trends and response to recent evidence. JAMA 291: 47-53.

Hulley S, Grady D, Bush T, et al. (1998). Randomized trial of estrogen plus progestin for secondary prevention of coronary heart disease in postmenopausal women: Heart and Estrogen/progestin Replacement Study (HERS) Research Group. JAMA 280: 605-13.

Johannes CB, Crawford SL, Posner JG, McKinlay SM (1994). Longitudinal patterns and correlates of hormone replacement therapy use in middle-aged women. Am J Epidemiol 140: 439-52.

Jolleys JV, Olesen F (1996). A comparative study of prescribing of hormone replacement therapy in USA and Europe. Maturitas 23: 47-53.

Keating NL, Cleary PD, Rossi AS, Zaslavsky AM, Ayanian JZ (1999). Use of hormone replacement therapy by postmenopausal women in the United States. Ann Intern Med 130: 545-53.

Khaw KT (1998). Hormone replacement therapy again. Risk-benefit relation differs between populations and individuals. BMJ 316: 1842-4.

Levy BT, Ritchie JM, Smith E, Gray T, Zhang W (2003). Physician specialty is significantly associated with hormone replacement therapy use. Obstet Gynecol 101: 114-22.

MacLennan AH, MacLennan A, Wilson D (1993). The prevalence of oestrogen replacement therapy in South Australia. Maturitas 16: 175-83.
McKinlay SM, Brambilla DJ, Posner JG (1992). The normal menopause transition. Maturitas 14 103-15.

Million Women Study Collaborators (2002). Patterns of use of hormone replacement therapy in one million women in Britain, 1996-2000. BJOG 109: 1319-30.

Moorhead T, Hannaford P, Warskyj M (1997). Prevalence and characteristics associated with use of hormone replacement therapy in Britain. Br J Obstet Gynaecol 104: 290-7.

Morabia A, Bernstein M, Heritier S, Ylli A (1997). Community-based surveillance of cardiovascular risk factors in Geneva: methods, resulting distributions, and comparisons with other populations. Prev Med 26: 311-9.

Mueller JE, Doring A, Heier M, Lowel H (2002). Prevalence and determinants of hormone replacement therapy in German women 1984-1995. Maturitas 43: 95-104.

Oddens BJ Boulet MJ (1997). Hormone replacement therapy among Danish women aged 45-65 years: prevalence, determinants, and compliance. Obstet Gynecol 90: 269-77.

Oddens BJ, Boulet MJ, Lehert P, Visser AP (1994). A study on the use of medication for climacteric complaints in western Europe-II. Maturitas 19: 1-12.

Posthuma WF, Westendorp RG, Vandenbroucke $J P$ (1994). Cardioprotective effect of hormone replacement therapy in postmenopausal women: is the evidence biased? BMJ 308: 1268-9.

Ringa V, Jaussent I (1999). Trends in the use of hormone replacement therapy in eastern France between 1986 and 1993. Eur J Public Health 9: 300-5.

Rossouw JE, Anderson GL, Prentice RL, et al (2002). Risks and benefits of estrogen plus progestin in healthy postmenopausal women: principal results From the Women's Health Initiative randomized controlled trial. JAMA 288: 321-33.

Stafford RS, Saglam D, Causino N, Blumenthal D (1997). Low rates of hormone replacement in visits to United States primary care physicians. Am J Obstet Gynecol 177: 381-7.

Taffe J, Garamszegi C, Dudley E, Dennerstein L (1997). Determinants of self rated menopause status. Maturitas 27: 223-9.
Women's Health Initiative Randomized Controlled Trial (2004). Effects of conjugated equine estrogen in postmenopausal women with hysterectomy. JAMA 291: 1701-12.

U. S. Preventive Service Task Force (1996). Report: postmenopausal hormone prophylaxis: guide to Clinical Preventive Services. 2nd ed. Lippincott: William and Wilkins.

U. S. Preventive Services Task Force (2002). Postmenopausal hormone replacement therapy for primary prevention of chronic conditions: recommendations and rationale. Ann Intern Med 137: 834-9.

Wise MR, Stewart DE, Liu P, Abramson BL (1999). Use of hormone replacement therapy among cardiac patients at a Canadian academic centre. CMAJ 161: 33-6.

Zhang P, Tao G, Anderson LA (1999). Prevalence of and factors associated with hormone replacement therapy counseling: results from the 1994 National Health Interview Survey. Am J Public Health 89: 1575-7.

Address for correspondence

Dr. Arabelle. Rieder Nakhlé

Policlinique de Médecine

Département de Médecine Communautaire

Hôpitaux Universitaires de Genève

24, rue Micheli-du-Crest

CH-1211 Genève 14

Tel. :+41-22-372-95-37

e-mail: arabelle.rieder-nakhle@hcuge.ch 